\title{
FORMULAÇÃO E CARACTERIZAÇÃO DE SUSPENSÃO PARA RECOBRIMENTO DE UREIA
}

\author{
B. de ZORZI ${ }^{1}$, F. B. D. NORA ${ }^{1}$, G. F. WESTPHALEN ${ }^{1}$, T. P. da COSTA ${ }^{2}$, G. S. ROSA ${ }^{2}$ \\ ${ }^{1}$ Universidade Federal do Pampa, Graduação em Engenharia Química \\ ${ }^{2}$ Universidade Federal do Pampa, Programa de Pós Graduação em Engenharia \\ E-mail para contato: gabrielarosa@unipampa.edu.br
}

\begin{abstract}
RESUMO - O papel positivo dos fertilizantes foi comprovado como o fator que, isoladamente, mais contribui para o aumento da produtividade agrícola. $\mathrm{O}$ nitrogênio ocupa posição de destaque dentre os elementos essenciais ao desenvolvimento das espécies vegetais, fornecido geralmente através da aplicação da ureia. No entanto, este insumo apresenta alta susceptibilidade à volatilização, que podem chegar a $80 \%$ em algumas condições. Para que haja a minimização destas perdas, o recobrimento da ureia é uma estratégia que vem sendo muito difundida atualmente. Este trabalho tem como objetivo formular e caracterizar uma suspensão de natureza polimérica, para recobrimento de ureia em leito de jorro, a fim de minimizar as perdas por volatilização, aumentar a produtividade e diminuir o custo do plantio. Para isso, foram formuladas quatorze suspensões com polímeros e plastificantes distintos, onde foram analisadas suas concentrações de sólidos e sua estrutura morfológica através da elaboração de filmes.
\end{abstract}

\section{INTRODUÇÃO}

A adubação é uma etapa muito importante em um plantio, sendo responsável por fornecer à planta todos os nutrientes necessários para que ela cresça com força e qualidade.

De acordo com Duarte (2007), a ureia é o fertilizante nitrogenado mais utilizado na agricultura brasileira e contém aproximadamente $45 \%$ de nitrogênio em sua composição. Sua utilização na agricultura vem crescendo expressivamente nas últimas décadas, possui fácil aplicação, e pode ser utilizada em vários tipos de solos e safras. Como desvantagem possui alta higroscopicidade e alto teor de volatilização, podendo chegar a $80 \%$ do total de ureia aplicada.

Segundo Cantarella (2007), muitas estratégias estão sendo desenvolvidas com o objetivo de minimizar as perdas de nitrogênio. Dentre estas estratégias, está incluído o uso da ureia recoberta, também conhecidos como fertilizantes de libertação lenta ou controlada.

Os fertilizantes de liberação controlada são produtos com propriedades de dissolução mais lenta no solo, obtidos através do recobrimento do fertilizante com materiais pouco permeáveis. A finalidade do encapsulamento é formar uma camada protetora contra os agentes causadores da perda de nutrientes e que esta proteção não interfira na disponibilização do nutriente a planta (Vitti e Reirinchs, 2007). 
Os principais tipos de recobrimentos utilizados para esta função são: soluções de enxofre, ceras e materiais poliméricos. Segundo Borsari (2013), apesar das pesquisas mostrarem que os produtos mencionados podem levar a menores perdas de nitrogênio e, consequentemente, aumentar a eficiência agronômica e ambiental, estes fertilizantes possuem custos de produção mais elevados, geralmente decorrentes de processos complexos de industrialização e agregação do custo do material de revestimento.

Este trabalho tem como objetivo formular e caracterizar uma suspensão de natureza polimérica, para recobrimento de ureia em leito de jorro, a fim de minimizar as perdas por volatilização, aumentar a produtividade e que seja composta por insumos de baixo custo.

\section{MATERIAIS E MÉTODOS}

Estabeleceu-se trabalhar com uma suspensão de natureza polimérica que tenha capacidade de fornecer uma superfície de recobrimento uniforme e de baixo valor comercial. Portanto, foram realizados testes com o objetivo de obter uma formação de filme liso e uniforme, mas com aumento da concentração de sólidos visando obter espessura de filme suficiente, para diminuir ou minimizar as perdas de nitrogênio por volatilização.

As suspensões foram formuladas a partir de estudos realizados anteriormente por Donida (2000) e Rosa (2010) para o recobrimento de ureia em leito de jorro, objetivando substituir o polímero Eudragit ${ }^{\circledR}$ por outro polímero que possui menor custo. A formulação das suspensões se basearam na mistura aquosa de gelatina, carboximetilcelulose, amido de milho, talco PA, glicerol, corante e o polímero comercial ColorSeed ${ }^{\circledR}$. A Tabela 1 apresenta a relação e concentração dos insumos utilizados em cada teste.

Tabela 1 - Concentrações de insumos em filmes biodegradáveis (\% em peso)

\begin{tabular}{|c|c|c|c|c|c|c|c|c|}
\hline Filme & Gelatina & Carboximetilc. & Amido & Corante & ColorSeed & Glicerol & Talco & Água \\
\hline 1 & 1 & & & 0,1 & & 3 & 9 & 86,9 \\
\hline 2 & & 1 & & 0,1 & & 3 & 9 & 86,9 \\
\hline 3 & & & 1 & 0,1 & & 3 & 9 & 86,9 \\
\hline 4 & 0,5 & 0,5 & & 0,1 & & 3 & 9 & 86,9 \\
\hline 5 & 0,5 & & 0,5 & 0,1 & & 3 & 9 & 86,9 \\
\hline 6 & & 0,5 & 0,5 & 0,1 & & 3 & 9 & 86,9 \\
\hline 7 & 0,33 & 0,33 & 0,33 & 0,1 & & 3 & 9 & 86,9 \\
\hline 8 & 1 & & & & 2 & 3 & 9 & 85 \\
\hline 9 & & 1 & & & 2 & 3 & 9 & 85 \\
\hline 10 & & & 1 & & 2 & 3 & 9 & 85 \\
\hline 11 & 0,5 & 0,5 & & & 2 & 3 & 9 & 85 \\
\hline 12 & 0,5 & & 0,5 & & 2 & 3 & 9 & 85 \\
\hline 13 & & 0,5 & 0,5 & & 2 & 3 & 9 & 85 \\
\hline 14 & 0,33 & 0,33 & 0,33 & & 2 & 3 & 9 & 85 \\
\hline
\end{tabular}


No preparo das soluções primeiramente pesaram-se os insumos nas suas devidas quantidades em uma balança analítica digital, depois, misturou-se metade da água a ser utilizada ao talco, para uma melhor homogeneização.

O agitador magnético foi posicionado sobre a base do agitador mecânico para que ocorresse simultaneamente agitação e aquecimento, o agitador mecânico foi utilizado, pois o agitador magnético proporciona apenas $170 \mathrm{rpm}$, sendo necessário $800 \mathrm{rpm}$ para realização eficiente do processo.

Após a homogeneização do talco foi acrescentado o glicerol (plastificante), seguido do

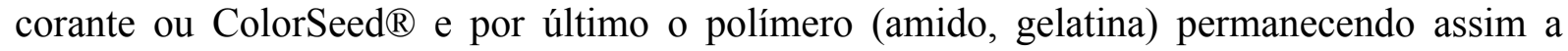
$70^{\circ} \mathrm{C}$ e $800 \mathrm{rpm}$ por aproximadamente 30 minutos.

Para auxiliar na escolha da formulação de recobrimento adequada foram preparados filmes, como mostra o fluxograma do procedimento de preparo mostrado na Figura 1.

Figura 1 - Procedimento experimental de preparação dos filmes

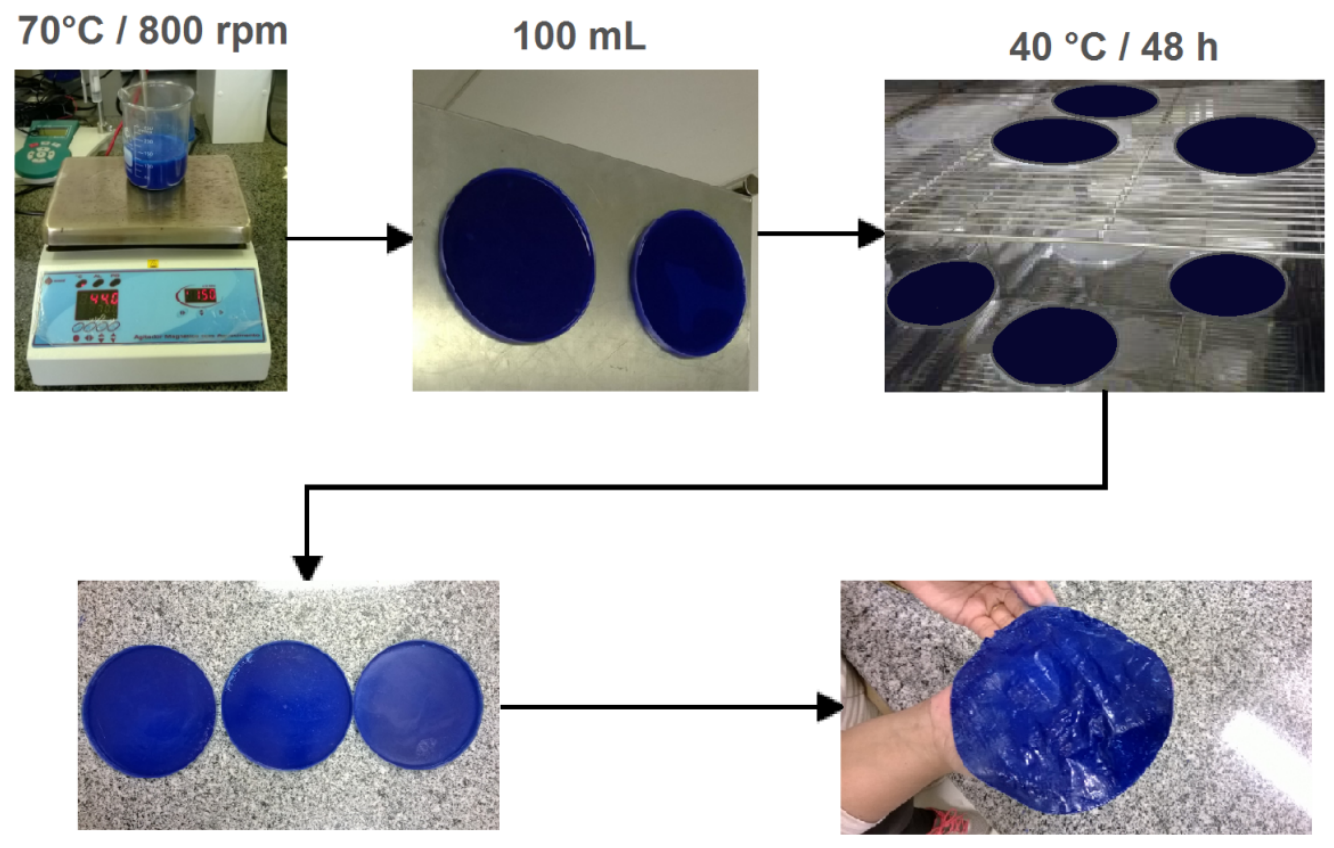

Conforme ilustrado na Figura 1, após o preparo da suspensão (100 mL cada) realizou-se a distribuição da amostra em placa de petri de acrílico, de diâmetro igual a $15 \mathrm{~cm}$. Os filmes foram obtidos pelo método de casting, ou método de deposição por espalhamento de solução, onde a solução é espalhada e em seguida, o solvente é eliminado por evaporação, resultando na formação de uma película (filme) do material desejado. Essas placas foram acondicionadas em estufa durante $48 \mathrm{~h}$ em temperatura de $40{ }^{\circ} \mathrm{C}$. Terminado o tempo de acondicionamento, os filmes foram retirados da placa acrílica. 
Terminado o tempo de acondicionamento, os filmes foram retirados da placa acrílica para análise de uniformidade e regularidade da superfície em microscópio óptico com ampliação de $250 \mathrm{X}$.

Também foram determinadas as concentrações de sólidos da suspensão, visto que se busca obter concentração de 10 a $15 \%$ de sólidos que, conforme literatura de DONIDA (2000) é uma concentração ótima para o processo de recobrimento. A determinação da concentração da suspensão foi feita através do método gravimétrico proposto pela Association of Official Analytical Chemists (AOAC, 1997). Esta análise foi realizada em triplicata e o método consistiu em manter as amostras em estufa a $105,5^{\circ} \mathrm{C}$ durante um intervalo de tempo de 24 horas. Para a determinação da umidade em base seca do material foi utilizada a Equação 1 .

$$
C_{s}=\frac{m_{s s}}{m_{t}}=\frac{m_{s s}}{m_{a}+m_{s s}}
$$

onde $m_{s s}$ é a massa de sólidos secos, $m_{t}$ é a massa total da amostra e $m_{a}$ é a massa de água contida na amostra.

\section{RESULTADOS E DISCUSSÃO}

Os filmes obtidos foram analisados quanto à uniformidade e regularidade da superfície em microscópio óptico. A Tabela 2 apresenta a superfície dos filmes de recobrimento obtida em microscópio óptico com ampliação de $250 \mathrm{X}$.

Tabela 2 - Micrografias da superfície dos filmes com ampliação de 250 X.

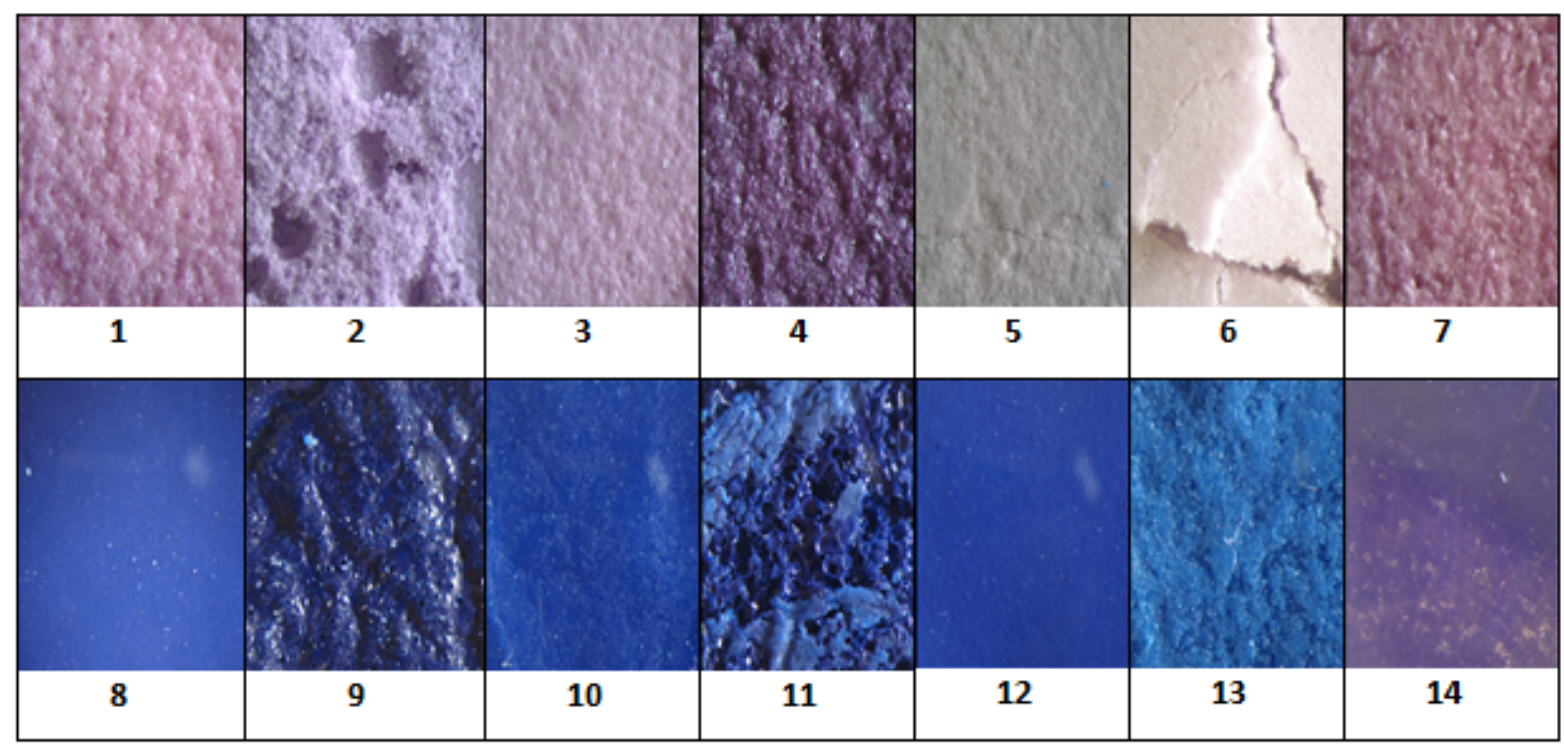

Como pode ser visto pelas micrografias apresentadas acima, os filmes 2, 4, 9 e 11 apresentaram-se menos homogêneos e uniformes que os demais filmes. 
Também foi observado que os filmes de concentração 3, 6, 7, 13 e 14 apresentavam-se mais quebradiços e menos flexíveis, impossibilitando algumas vezes a sua retirada da placa sem que se rompessem.

Já os filmes 1, 5, 8, 10 e 12 apresentaram-se mais homogêneos e contínuos e durante o preparo mostraram-se mais fáceis de manipular em relação aos demais, o que facilita a agitação e transferência para as placas. No entanto, as suspensões 1, 5 e 10 apresentaram algumas irregularidades na superfície.

Observou-se que a adição do polímero ColorSeed ${ }^{\circledR}$ tornou, tanto a suspensão filmogênica quanto o filme, mais uniformes do que os filmes sem a adição deste polímero. Isso indica que a adição do polímero aos filmes, causou alterações na morfologia e nas propriedades mecânicas do material.

Apesar de todas as suspensões contendo ColorSeed ${ }^{\circledR}$ terem passado pelo mesmo procedimento de mistura e agitação constante que as suspensões sem o polímero, ainda observou-se a presença de alguns pontos brancos nos filmes após a secagem. Dessa forma, há indícios que o talco pode não ter sido totalmente dispersado na suspensão, já que este possui a característica de se aglomerar em pequenas porções, o que torna bastante difícil sua total dispersão na solução filmogênica.

Foram determinadas as concentrações das suspensões filmogênicas e os resultados são apresentados na Tabela 2 .

Tabela 2 - Concentração de sólidos das suspensões filmogênicas

\begin{tabular}{cccc}
\hline Suspensão & $\begin{array}{c}\text { Concentração de sólidos } \\
\text { /desvio padrão }(\%)\end{array}$ & Suspensão & $\begin{array}{c}\text { Concentração de sólidos } \\
\text { /desvio padrão (\%) }\end{array}$ \\
\hline 1 & $12,89 \pm 0,44$ & 8 & $14,73 \pm 1,46$ \\
2 & $9,74 \pm 1,53$ & 9 & $11,38 \pm 2,27$ \\
3 & $11,60 \pm 1,79$ & 10 & $11,89 \pm 2,33$ \\
4 & $11,13 \pm 2,13$ & 11 & $10,73 \pm 0,86$ \\
5 & $11,70 \pm 2,12$ & 12 & $12,85 \pm 0,43$ \\
6 & $10,92 \pm 1,09$ & 13 & $10,97 \pm 1,30$ \\
7 & $10,84 \pm 2,45$ & 14 & $11,91 \pm 1,14$ \\
\hline
\end{tabular}

Através da Tabela 2 pode-se observar que os novos testes de formulações estão de acordo com a faixa sugerida por Donida (2000) para fornecer um recobrimento eficiente às partículas de ureia sem que haja o entupimento do bico atomizador.

Através das análises morfológicas dos filmes e dos resultados de concentração, prosseguiu-se com testes preliminares de atomização com as suspensões 8 e 12 . 
Pelos testes de atomização, onde a suspensão foi passada pelo bico atomizador com a ajuda de uma bomba peristáltica, a suspensão 8 ocasionou o entupimento do bico atomizador quando esta foi atomizada, o que pode estar associado ao fato dessa formulação conter maior concentração de sólidos.

Portanto, pelos testes preliminares realizados, optou-se por utilizar a suspensão 12 para os ensaios de recobrimento de ureia futuro, pois esta suspensão apresentou melhores resultados com relação à superfície do filme formado e em termos de operação e condução do processo de atomização, apresentando também razoável concentração de sólidos.

\section{CONCLUSÃO}

A concentração de sólidos das suspensões de recobrimento formuladas encontraram-se entre 9,74 e 14,73 \% indicando que estão de acordo com a faixa sugerida pela literatura para fornecer um recobrimento eficiente às partículas de ureia.

Através das análises morfológicas dos filmes optou-se por utilizar a suspensão de 12 ( $0,5 \%$ gelatina, $0,5 \%$ amido e $2 \%$ ColorSeed ${ }^{\circledR}$ ) os ensaios de recobrimento de ureia futuro, pois esta suspensão apresentou melhores resultados com relação à superfície do filme formado e em termos de operação e condução do processo de atomização.

\section{REFERÊNCIAS}

AOAC. Association of Official Analytical Chemists. Official methods of analysis. 16. ed., 3. rev, v. 2, Gaitherburg: Published by AOAC International, 1997.

BORSARI, F. Fertilizantes inteligentes: As novas tecnologias permitem o consumo dos nutrientes pelas plantas de forma gradativa, lenta e controlada. Agro DBO, São Paulo, $\mathrm{N}^{\mathrm{o}}$ 45, jun. 2013.

CANTARELlA, H. Nitrogênio. In: NOVAIS, R. F. Fertilidade do solo. 2. ed. Sociedade Brasileira de Ciência do Solo, Viçosa. p.375-470, 2007.

DONIDA, M. W. Recobrimento Polimérico da Ureia em Leito de Jorro Bidimensional. Dissertação (Mestrado em Engenharia Química), Universidade Estadual de Campinas, 2000.

DUARTE, D. S. A. Perdas de amônia por volatilização em solo tratado com ureia, na presença de resíduos cultuais. Dissertação (Mestrado em Solos e Nutrição de Plantas) Escola Superior de Agricultura "Luiz de Queiroz", Universidade de São Paulo, Piracicaba, 2007.

ROSA, G. S. Recobrimento de Ureia em Leito de Jorro para Minimizar as Perdas de Nitrogênio por Volatilização. Dissertação (Mestrado em Engenharia Química)Universidade Estadual de Campinas. Campinas, 2012.

VITTI, G. C.; REIRINCHS, R. Formas tradicionais e alternativas de obtenção e utilização do nitrogênio e do enxofre: uma visão Holística. In: YAMADA, T.; STIPP, S. R.; VITTI, G. C. Nitrogênio e Enxofre: na agricultura brasileira. IPNI: Piracicaba, p. 109 -157, 2007. 